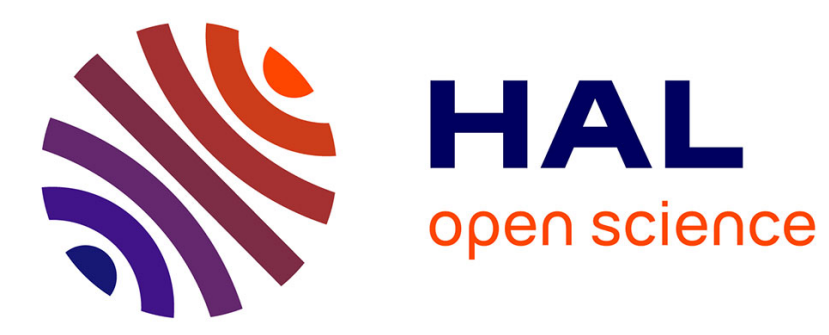

\title{
Etat de la recherche archéologique concernant la période ottomane en Bulgarie
}

\author{
Guergana Guionova
}

\section{To cite this version:}

Guergana Guionova. Etat de la recherche archéologique concernant la période ottomane en Bulgarie. Turcica: revue d'études turques, 2005, 37, pp.267-279. halshs-00505553

\section{HAL Id: halshs-00505553 \\ https://shs.hal.science/halshs-00505553}

Submitted on 10 Feb 2015

HAL is a multi-disciplinary open access archive for the deposit and dissemination of scientific research documents, whether they are published or not. The documents may come from teaching and research institutions in France or abroad, or from public or private research centers.
L'archive ouverte pluridisciplinaire HAL, est destinée au dépôt et à la diffusion de documents scientifiques de niveau recherche, publiés ou non, émanant des établissements d'enseignement et de recherche français ou étrangers, des laboratoires publics ou privés. 


\section{ÉTAT DE LA RECHERCHE ARCHÉOLOGIQUE CONCERNANT LA PÉRIODE OTTOMANE EN BULGARIE*}

a richesse des sources écrites conservées, traduites, publiées et mises à la disposition des spécialistes, est une donnée importante pour l'ensemble de l'historiographie concernant l'époque ottomane en Bulgarie. Les grandes quantités d'archives dans les fonds des bibliothèques (et surtout ceux de la Bibliothèque Nationale) ont attiré très tôt l'intérêt des philologues et des historiens. Depuis le début du siècle dernier (Тодоров, Калицин, 1977), le travail sur ces sources a permis d'accumuler des connaissances dans les différents domaines de l'histoire bulgare de la période ottomane: l'économie, l'administration, la politique, la démographie et la sociologie. Dans les années 70 et 80 , plusieurs travaux de synthèse et des actes de colloques ont montré l'importance des études menées non seulement à l'échelle nationale mais sur l'ensemble du territoire balkanique de l'Empire ottoman (Beldiceanu, 1973; Cvetkova, 1978; Паскалева et al., 1978; Mollat et al., 1985).

Par ailleurs, depuis le début du siècle également, les études ethnographiques se sont développées intensivement. De nature plutôt descriptive au départ, leur accumulation a permis la parution, ces dernières décen-

Guergana GUIONOVA est doctorante, Institut et musée d'archéologie (Sofia), et Laboratoire d'archéologie médiévale méditerranéenne (UMR 6572), MMSH, 5 rue du Château de l'Horloge, BP 647, 13094 — Aix-en-Provence Cedex.

guionova@mmsh.univ-aix.fr

* Cet article ne prétend pas être une recherche exhaustive sur la bibliographie de l'archéologie ottomane en Bulgarie qui reste encore à faire. Les références bibliographiques fournies sont là pour appuyer les données exposées. 
nies, de travaux plus approfondis et plus synthétiques sur le rituel et le quotidien du système traditionnel bulgare (Маринов, 1914; Лулева, 2002).

Il est nécessaire de présenter les acquisitions de la connaissance historique au sens très large, concernant la période de l'occupation ottomane en Bulgarie. Les résultats de cette documentation donnent le cadre, et souvent la base, de l'apparition et de l'évolution d'un autre domaine de la recherche historique - l'archéologie ottomane. Ils sont porteurs de renseignements précieux sur l'organisation et la production de différents artisanats, sur la structure urbaine et la création architecturale, sur les matières de production et d'échanges commerciaux — en bref, sur l'ensemble de la culture matérielle et ses caractéristiques ethniques et sociales.

L'archéologie ottomane en Bulgarie n'est pas à ses débuts. Elle a subi pourtant un certain retard malgré la connaissance du cadre historique. En réalité, il a fallu attendre ces dernières décennies pour observer une démarche plus systématique de croisement des données historiques avec le matériel archéologique afin d'illustrer et de compléter le savoir déjà existant. Les raisons de ce décalage, alors que l'archéologie en Bulgarie dans son ensemble s'est développée dans les traditions et avec la méthodologie des grandes écoles européennes, sont multiples.

D'abord, et de façon plus évidente, on peut évoquer le manque de décalage chronologique entre la période ottomane, considérée souvent dans son ensemble, et l'époque contemporaine. D'une part, le XVIII ${ }^{\mathrm{e}}$ siècle, la fin de cette époque d'après la périodisation de l'histoire bulgare, paraît assez proche pour permettre de placer les couches stratigraphiques les plus récentes dans le domaine de l'archéologie. D'autre part, le décalage chronologique est nécessaire également pour laisser place à une analyse «non-émotionelle » des données historiques. Dans l'historiographie bulgare, la période ottomane n'a pas encore trouvé les termes de son caractère : joug, occupation, domination, régime, présence...

Cette «non-réalisation» de l'archéologie ottomane résulte aussi de la mentalité, au sens sociologique du mot, constituée par le vécu historique des Bulgares. A ce propos, B. Lory présente de façon un peu absolue le rejet «par principe» de la culture ottomane par les Bulgares (Lory, 1985, p.1-10) mais exprime assez exactement la notion d' «orientalchtina » associée non seulement au comportement mais aussi au goût et, par conséquent, à la réalité matérielle attribués à la culture ottomane et à son héritage. Il dérive de cette situation sinon un refus, du moins un certain désintérêt du passé matériel de la période ottomane. 
A cela s'ajoute, dans le contexte de l'archéologie, une sorte d'attachement à la période précédente, celle du Deuxième royaume bulgare $\left(\mathrm{XII}^{\mathrm{e}}\right.$ $\mathrm{XIV}^{\mathrm{e}}$ siècles), temps de prospérité de la politique et de la culture bulgares. Cette préférence provoque parfois un glissement d'un certain nombre de données de la stratigraphie ottomane vers l'époque précédente. Ces datations erronées ne sont évidemment pas faites sciemment. Il faut ici souligner le manque de parallèles bibliographiques disponibles pour les spécialistes bulgares. Les comparaisons avec du matériel publié étaient encore récemment limitées non seulement pour le territoire bulgare mais aussi pour l'ensemble des pays balkaniques.

Enfin, la dernière raison, mais non la moindre, est d'ordre économique et freine l'ensemble de l'activité archéologique en Bulgarie ainsi que la publication des recherches menées malgré tout. En réalité, la période des dix-quinze dernières années coïncide malheureusement avec la prise de conscience de plus en plus systématique et l'engagement de nombreux archéologues vers une objectivité stratigraphique et matérielle.

Toutes ces raisons traduites par le manque de temps, de moyens, d'intérêt, ont amené encore récemment sur le terrain à des pratiques parfois malheureuses comme «le nettoyage» des couches supérieures. A cela s'ajoute parfois le résultat de la mécanisation des chantiers archéologiques dont l'usage abusif détruit la stratigraphie la plus récente (Ваклинова, 2001).

La recherche archéologique sur la période ottomane en Bulgarie et ses résultats sont tout de même une réalité et ne sont pas le fruit de trouvailles fortuites. Différents sujets ont été abordés et développés dans les publications depuis les années trente et, de façon proportionnelle au développement de l'activité archéologique, dans les années soixante. Si le début de ce texte mettait l'accent sur la connaissance des sources et des données ethnographiques, c'est parce que l'évolution de l'archéologie en était souvent dépendante.

Depuis les années trente et surtout dans les années soixante du siècle dernier, l'historiographie bulgare a accumulé des connaissances sur les sources écrites et l'épigraphie concernant l'architecture ottomane (Zajaczkowski, 1966; Татарль, 1966). A la même période, à ces études s'ajoutent des observations et des recherches sur les monuments euxmêmes (Рудолф-Хиле, Рудлф, 1934; Mijatev, 1959; Кантарджиев, 1966). Dès lors, les données archéologiques au sens strict et concernant surtout les mosquées apparaissent dans les publications, de façon ponc- 
tuelle au départ (Георгиева, 1967) et sous forme d'études plus détaillées lors des dernières décennies (Генова, 2000). Des fouilles archéologiques leur ont été spécialement consacrées (Petrounova, Vaklinov, 2000) et les plus récentes sont en cours de publication. Dans les années quatre-vingt-dix, paraissent également des études de synthèse concernant l'urbanisme et l'architecture des XVe-XVIII ${ }^{\mathrm{e}}$ siècles (Xapбова, 1991). En réalité, l'architecture ottomane avait sa place au sein du patrimoine tel qu'il était conçu par les historiens bulgares — dans un des premiers guides «touristiques », celui de Véliko Tarnovo, la mosquée de Firuz-beg y figurait (Пьтеводител, 1907). Seulement, son intégration dans la problématique archéologique, en tant que discipline à part entière, est plus récente.

Les riches connaissances ethnographiques ont également facilité l'approche de l'archéologie funéraire. Le système rituel traditionnel a souvent servi de base pour l'interprétation des données archéologiques recueillies lors des fouilles de nécropoles tardives (Миков, 1933; Петрунова, 1992). Les monuments tombeaux ont donné matière à des études épigraphiques et, de manière plus générale, à des recherches sur les caractéristiques et le symbolisme de ce type de sculpture (Райнов, 1923; Петров, 1962; Герасимов, 1962; Петров, 1968; Драганова, Димитров, 1987). L’archéologie funéraire a fourni également des éléments de costume et de parures qui ont illustré ou complété les sources ethnographiques. Si une étude approfondie n'existe pas encore à ce sujet, cette problématique n'échappe plus aux préoccupations scientifiques des archéologues bulgares (Овчаров, 1971). De façon plus générale, les données ethnographiques et le travail de terrain ont été conjointement mis à contribution lors des recherches plus approfondies sur les lieux de cultes (Петрунова, Григоров, МаноловаНиколова, 2001).

Le matériau archéologique qui a surtout bénéficié d'attention de la part des archéologues est la céramique. Ceci n'est pas dû au hasard: la connaissance sur la production et la consommation de céramique de la période précédente est assez riche; en tant que produit d'une activité artisanale, son étude puise de précieux (bien que rares) renseignements dans les archives; sa nature commune et sa fréquence ont facilité son analyse.

En réalité, la recherche sur la céramique de l'époque ottomane s'appuie d'abord sur des collections. Les raisons évoquées plus haut ont souvent privé le matériel tardif de son contexte archéologique mais des «té- 
moins », surtout les mieux conservés, ont trouvé leur place dans les fonds des musées. Evidemment, le plus souvent les publications présentent les productions céramiques connues déjà par des parallèles bibliographiques - c'est le cas des pipes des collections de Sofia, Varna, Provadia et Nicopol (Станчева, Медарова, 1968; Станчева, 1972; Хараламбиева, 1986 ; Аспарухов, 1997), de la faïence turque (Станчева, 1960) et italienne (Станчева, 1962) du musée de Sofia ou de la porcelaine de Meissen et de Vienne des musées de Nicopol (Манова, 1983 ) et de Sofia (Станчева, Шалаганова, 1989). Par ailleurs, des formes plus rares ou particulières ont attiré l'attention et fait l'objet de publications: les pots des poêles de chauffage (Станчева, Кръстанова, 1967 ; Бучински, 1970) ou les récipients pour la distillation comme les alambics étudiés par I. Alexiev (Алексиев, 1992).

Les collections des fonds ethnographiques des musées ont également fourni de la matière pour des études et des informations sur la culture matérielle de la période ottomane. C'est le cas notamment des pipes, comme celles de Chumen (Божилова, Сиракова, 1991), déjà connues par les recherches archéologiques (Сиракова, 1989). En revanche, les études sur les collections de récipients en cuivre des musées de Chumen (Дочева-Попова, 1973) et de Véliko Tarnovo (Стефанова, 1989) ont livré de nouveaux renseignements sur l'artisanat du cuivre des régions de ces villes. Un travail universitaire avait même fait le point sur cette production à échelle nationale (Ковачева-Костадинова, 1979).

Le matériel archéologique complète les connaissances par des publications plus ou moins détaillées, concernant souvent la céramique: des formes particulières comme un «service» de chopes et les tirelires de Sofia (Станчева, 1966) ou bien des des formes plus fréquentes, les cruches, vues dans leurs typologie et évolution (Stanceva, 1994) ou la céramique à fonction hygiénique des fouilles de Varna (Плетньов, 2000a). Dans les années quatre-vingt, des publications déterminent la continuité dans la production potière de certains centres et présentent la céramique tardive de Melnik (Цветков, 1981), Véliko Tarnovo (Алексиев, 1977 ; Генова, 1983), Varna (Кузев, 1983; Кузев, 1984). Par la suite, des études à plus grande échelle sont faites sur la céramique de production et de consommation de ces centres (Цветков, 1989; Генова, 1993а; Плетньов, 2000b). Il est intéressant de remarquer que c'est justement l'artisanat de la céramique de l'époque ottomane qui a bénéficié d'une systématisation terminologique (Генова, 1993b) — un acquis rare pour le travail sur la matière archéologique en Bulgarie. 
Les résultats de la recherche archéologique de l'époque ottomane ont été également enrichis par la révision de certaines datations attribuées initialement aux $\mathrm{XII}^{\mathrm{e}}-\mathrm{XIV}^{\mathrm{e}}$ siècles. Les exemples les plus connus concernent encore une fois la céramique. Ainsi, dans les années soixante, la sgraffito a obtenu une identité en tant que type de céramique de production continue, détachée de la culture matérielle du Deuxième royaume bulgare et dissociée du «type de Tarnovo » comme elle était connue jusqu'alors (Станчева, 1964). C'est dans les années soixante-dix que la production de Varna, connue aussi par les rebuts de cuisson et datée, dix ans auparavant, dans les XII ${ }^{\mathrm{e}}-\mathrm{XIV}^{\mathrm{e}}$ siècles (Дими ров, 1960), est finalement attribuée à la période ottomane (Кузев, 1976).

Il est évidemment impossible, dans le cadre d'une publication de mise au point de l'état de la recherche archéologique, de détailler toutes les matières et publications relatives à la période qui nous intéresse. Par respect de la réalité, il est tout de même important de remarquer que, de façon générale, lors des dernières décennies, les structures, la numismatique, la céramique et d'autres matériaux tardifs sont souvent présentés dans les publications des fouilles. C'est d'autant plus courant quand il s'agit de matière datante et, donc, d'exemples ayant des parallèles bibliographiques. Pour illustrer la variété des matières traitées, on peut juste évoquer deux études sur les graffitis des églises : à Véliko Tarnovo, où les sujets sont des jongleurs et des chevaux, peut-être de cirque (Овчаров, Овчаров, 1985); à Nessebar où les représentations ont donné matière à une recherche sur la navigation le long de la côte bulgare de la mer Noire (Овчаров, 1992).

Les références bibliographiques citées jusque là reflètent une des particularités des publications sur l'archéologie ottomane en Bulgarie - si la chronologie de la période n'est pas vue dans son ensemble, souvent un découpage se dessine entre les $\mathrm{XV}^{\mathrm{e}}-\mathrm{XVII}^{\mathrm{e}}$ et les $\mathrm{XVIII}{ }^{\mathrm{e}}-\mathrm{XIX}^{\mathrm{e}}$ siècles. La première partie de la période est généralement présentée à travers le prisme «continuité-rupture», en rapport avec les connaissances sur l'époque précédente. En revanche, pour les XVIII ${ }^{\mathrm{e}}-\mathrm{XIX}^{\mathrm{e}}$ siècles, on dispose de davantage de données précises et d'études approfondies. Cela est dû surtout à la richesse du savoir ethnographique évoquée plus haut mais aussi à une certaine préférence pour la période de la Renaissance bulgare, c'est-à-dire le XVIII ${ }^{e}$ siècle qui voit la renaissance de la conscience nationale. C'est donc une période qui a suscité beaucoup de recherches sur les facteurs de formation du système esthétique et culturel des Bulgares à la veille et au début de leur indépendance. 
L'archéologie, dans son rôle d'étude de la culture matérielle, ne peut pas s'éloigner des considérations faites sur son caractère, plus propres à l'histoire de l'art. De fait, dans les publications, l'accent est mis souvent sur l'analyse stylistique, sur les qualités esthétiques et les traits ethniques de l'origine et des influences de la matière archéologique. A cela s'ajoutent les observations d'ordre économique et social qui déterminent l'organisation et la qualité de la création matérielle (Станчева, 1976; Генова, 1993). En réalité, les auteurs sont toujours soucieux de déterminer les parts de l'héritage byzantin, des influences orientales, d'Asie centrale et d'Asie Mineure, et de l'Europe occidentale. On cherche à cerner le côté authentique de l'art bulgare; à connaître la limite entre les moyens économiques et les besoins esthétiques d'une production artisanale. Voilà pourquoi une des études qui fait le point sur la connaissance de la culture matérielle, à l'époque ottomane en Bulgarie, est plutôt un ouvrage d'histoire de l'art, qui traite d'architecture, des arts appliqués et figuratifs dans leur évolution et sur l'ensemble de la péninsule Balkanique (Стайнова, 1995). En passant, il faut mentionner que l'analyse stylistique est propre à l'école archéologique bulgare. Elle prend souvent le dessus lors d'étude des artefacts des périodes précédentes et cela toujours en raison de la quête des caractéristiques de la culture nationale, de sa formation et son évolution.

Il faut souligner, en conclusion, que le développement de l'archéologie ottomane, en Bulgarie, s'appuie sur des bases solides: d'une part, grâce à une bonne connaissance de l'archéologie antérieure et à la maîtrise des méthodes de recherche sur le terrain; d'autre part, grâce au savoir historique et ethnographique accumulé par l'historiographie. Il faut espérer que, dans l'avenir, des travaux de synthèse à échelon national viendront rassembler la documentation parfois éparse et que cette discipline bénéficiera des moyens lui permettant de compléter les données historiques par des observations d'ordre technique: la stratigraphie du terrain, les diverses analyses de laboratoire, les études sur les techniques de production... Voilà des éléments qui, rajoutés aux acquis, pourront pallier à la connaissance de la vie matérielle de l'époque ottomane en Bulgarie, mais aussi enrichir en retour le domaine de l'histoire. 


\section{BIBLIOGRAPHIE}

Тодоров, Калицин, 1977: ТОДОРОВ Николай, КАЛИЦИН Мария. Турски извори за българската история, VI (Наследствени описи и покупко-продажбени протоколи от кадийските регистри на София, XVII-XIX в.). София: БАН, 1977, 431 стр. (Извори за българската история, XXI).

Cvetkova, 1978: CVETKOVA Bistra, Les Institutions ottomanes en Europe, Wiesbaden, Franz Steiner Verlag GMBH, 1978, 117 p.

Beldiceanu, 1973 : BELDICEANU Nicoara, Recherche sur la ville ottomane au XVe siècle. Etude et actes, Paris, éd. A. Maisonneuve, 1973, 466 p. (Bibliothèque archéologique et historique de l'Institut français d'archéologie d'Istanbul, XXV).

Паскалева et al., 1978: ПАСКАЛЕВА Виргиния., ПАНОВА Снежка., БЕРОВ Любен., ЦВЕТКОВА Бистра. (ред.) - Из историята на тврговията в българските земи през $X V$-XIX в. София: БАН, Институт по история, 1978. 261 стр. (Изследвания по българска история, 2).

Mollat et al., 1985: MOLLAT Michel, TODOROV Nikolaj, VILLAINGANDOSSI Christiane, TODOROVA Elisaveta (réd), Le pouvoir central et les villes en Europe de l'Est et du Sud-Est du XVe siècle aux débuts de la révolution industrielle. Les villes portuaires, Sofia, éd. de l'Académie Bulgare des Sciences, 1985, $270 \mathrm{p}$.

Лулева, 2002 : ЛУЛЕВА Ана, Светът на вещите в традииионния български дом. София: Академично издателство «Проф. Марин Дринов », 200,. $254 \mathrm{c}$.

Маринов, 1914: МАРИНОВ Димитър. - Народна вяра и религиозни народни обичаи. Сборник народни умотворения, 28, 1914.

Lory, 1985: LORY Bernard, Le sort de l'héritage ottoman en Bulgarie. L'exemple des villes bulgares 1878-1900, Istanbul, éd. Isis, 1985, 235 p. (Publié à l'initiative et avec le concours de l'Institut français d'études anatoliennes d'Istanbul et de l'Association pour le développement des études turques (Paris)).

Zajaczkowski, 1966: ZAJACZKOWSKI A., Materialy do epiggrafiki osmansko-tureckiej z Bulgarii, Rocznik Orientalistyczny, XXVI/2, 1963, c. 13-15.

Татарль, 1966: ТАТАРЛЬ И. - Турски култови сгради и надписи в България. Годишник на софийския Университет, фзф, 1966, стр. 578-579.

Рудолф-Хиле, Рудлф, 1934 : РУДОЛФ-ХИЛЕ Г., РУДОЛФ О. - Град Пловдив и неговите паметниии. Известия на Българския археологически институт, VIII, 1934, стр. 389.

Mijatev, 1959: MIJATEV Petar, Les monuments osmanlis en Bulgarie, Rocznik Orientalistyczny, XXIII/1, 1959, p. 16.

Кантарджиев, 1966: КАНТАРДЖИЕВ П. - Архитектурни паметници на османските турци в българските земи. In: Кратка история на бългаската архитектура. София, 1966, стр. 185. 
Георгиева, 1967: Георгиева Соня. - Нови данни за иврквата «Св. Петка» и за джсамията ня Царевеи във Велико Търново. Археология, IX, кн. 2. 1967, стр. 29-30.

Генова, 2000: ГЕНОВА Златка. - Джамията на Фируз-бег. In: НЕШЕВА Виолета. - Богоспасният Цариград Търнов, Двориовият площад на Царевеч и иърквата на Света Параскева (Петка) Търновска - история, археология, изкуство. София: ALEA, 2000, стр. 203-224.

Petrounova, Vaklinov, 2000: PETROUNOVA Boni, VAKLINOV Michail, «L'ancienne Mosquée de Gotze Delcev», Bulletin de la Fondation Max van Berchem, 14, 2000, p. 5-7.

Пътеводител, 1907: Пътеводител на град В. Търново и околността му. Търново, 1907.

Миков, 1933 : Миков Васил. - Български гробища от XV-XVII в. до с. Калугерица (Новопазарска околия). Българска историческа библиотека, т. 5. 1932-33. т. 2. с. 163-164.

Петрунова, 1992 : ПЕТРУНОВА Бони. - Късносредновековен некропол в Калугерица. In: ОВЧАРОВ Димитър, ЩЕРЕВА Ирина (ред.). - Приноси към бългаската археология, І. София: Аргес, 1992. с. $271-279$.

Петрунова, Григоров, Манолова-Николова, 2001 : ПЕТРУНОВА Бони, ГРИГОРОВ В., МАНОЛОВА-НИКОЛОВА Мария. - Свети места в Годечко, Драгоманско и Трънско. София : 2001.

Райнов, 1923: РАЙНОВ Николай. - Копривщенски надгробни кръстове, плочи и зидани извори. Годишник на народната библиотека в Пловдив, 1923.

Герасимов, 1962: ГЕРАСИМОВ Т. - Един български паметник от $X V I$ в. Известия на института за българск език, 7, 1962. с. 55-61.

Драганова, Димитров, 1987: ДРАГАНОВА Т., ДИМИТРОВ Й. $-3 a$ някои по-забележстелни надгробни плочи от XVIII-ХІХ в. във В. Търново, Арбанаси и околните селища. ГМСБ, ХІІІ. 1987. с. $107-$ 124.

Петров, 1962: ПЕТРОВ П., Кръговидни паметниии в западна България. Археология, кн. 2, 1962, с. 17-24.

Петров, 1968 : ПЕТРОВ П., Реликтни декоративни елементи на оброчните и гробните паметничи в Северозпадна България. Музеи и паметници на културата, т. 3, 1968, с. 43-48.

Овчаров, 1971: ОВЧАРОВ Димитьр. - За един средновековен накит за глава през късното средновековие. Музеи и паметници на културата, т. 3. 1971, с. 16-20.

Станчева, Медарова, 1968: СТАНЧЕВА Магдалина, МЕДАРОВА Ст. - Производство на глинени лули у нас. Музеи и паметници на културата, 4, 1968, стр. 4-13.

Станчева, 1972: СТАНЧЕВА Магдалина. - Колекиия яули във Варненския музей. Известия на Народния Музей - Варна, 8, 1972. стр. 81-98. 
Хараламбиева, 1986: ХАРАЛАМБИЕВА Ана. - Лули за чибучи от градския музей в Провадия. Известия на Народния Музей Варна, 22, 1986, стр. 141-147.

Станчева, 1960 : СТАНЧЕВА Магдалина. - Турски фаянс от София. Извистия на Археологическия Институт, XXIII. София: БАН, 1960, стр. 111-143.

Станчева, Кръстанова, 1967 : СТАНЧЕВА Магдалина, КРЪСТАНОВА Киприяна. - За зиданата домашна печка в нашите земи през епохата на турското владичество. Известия на Етнографския институт и музей, т. Х, 1967. София: БАН, 1967, стр. 129-141.

Станчева, 1962: СТАНЧЕВА Магдалина. - Флорентинска майолика om XV в., намерена в София. Извистия на Института за Изобразителни изкуства, кн. V, 1962. София: БАН, 1962, стр. 161-165.

Манова, 1983: МАНОВА Екатерина, Саксонски пориелан в Никопол. Интердисциплинарни изследвания, Х, 1983. София: БАН, 1983, стр. 73-83.

Станчева, Шалаганова, 1989: СТАНЧЕВА Магдалина, ШАЛАГАНАВА Татяна. - Археологечески данни за внос на западен порцелан в София през XVIII и XIX в. In: Сердика, том 2 : археологически материали и проучвания. София : БАН, 1989, стр. 124132.

Бучински, 1970 : БУЧИНСКИ Д, Дегларско производство във Врача от $X V$ до XVIII век. Музеи и паметници на културата, год. X, кн. 1. 1970, стр. 13.

Харбова, 1991: ХАРБОВА Маргарита, Градоустройство и архитектура по българските земи през XV-XVIII век. София : БАН, 1991.

Божилова, Сиракова, 1991 : БОЖИЛОВА Петрана, СИРАКОВА Илина. — Лули и чибучи от фонда на отдел «Етнография» при историческия музей - Шумен. Годишник на музеите от Северна България, кн. XVII, 1991, стр. 165-173 + 4 таб.

Сиракова, 1989: СИРАКОВА Илина. - Глинени лули за чибуци от Шуменската крепост. Годишник на музеите от Северна България, кн. XV, 1989, стр. 91-95.

Дочева-Попова, 1973: ДОЧЕВА-ПОПОВА Евгения, Към въпроса за медникарството в Шумен. Известия на народния музей - Шумен, кн. VI, 1973, стр. 311-328.

Стефанова, 1989: СТЕФАНОВА Неда, Медникарският занаят и колекииятя от медни съдове, съхранявани във фонда на музея Велико Търново. Годишник на Музеите от Северна България, кн. XV, 1989, стр. 151-163 + ХІ таб.

Ковачева-Костадинова, 1979: КОВАЧЕВА-КОСТАДИНОВА В. А., Български медни съдове. произход, развитие, етническа спечифика. Автореферат на дисертация. София: 1979, 23 стр.

Аспарухов, 1997: АСПАРУХОВ Милко, Археологически приноси към историята на средновековния Никопол. Част пьрва. Враца, 1997, 175 с. (Библиотека «Български Северозапад» към «Известия на музеите от Северозападна България », 13). 
Станчева, 1966: СТАНЧЕВА Магдалина, Към изучаването на градската култура и бит в София през турското владичество. Известия на Етнографския институт и музей, IX, 1966, стр. 271-279.

Stanceva, 1994: STANCEVA Magdalina, L'aiguière de table bulgare du XV au XVII ${ }^{\mathrm{e}}$ s., in: OVCAROV D. (red), La culture materielle et l'art dans les terres bulgares VIe-XVIIe s., Bulletin de l'Institut d'archéologie, XXXVIII, 1994, Sofia, éd. académiques «Prof. Marin Drinov», 1995, p. $117-132$.

Плетньов, 2000а: ПЛЕТНЬОВ Валентин, Хигиенни съдове от XVI в. началото на XIX в. от Варна. Археология, кн. 3-4, год. XLI, 2000, c. $84-90$.

Цветков, 1981 : ЦВЕТКОВ Борис, Художествена керамика от Мелник. Албум. София, 1981.

Генова, 1983 : ГЕНОВА Златка, Късносредновековна керамика с рисувана украса от Търново. Векове, кн. 2, 1983, с. 66-70.

Алексиев, 1977: АЛЕКСИЕВ Йордан, Керамична пещ от XVIII 8. на хълма Царевец. Музеи и паметници на културата, 3, 1977, c. 8-13.

Алексиев, 1992: АЛЕКСИЕВ Йордан, Средновековни дестилаиионни сьдове. In: ОВЧАРОВ Димитьр, ЩЕРЕВА Ирина (ред.). - Приноси кьм бьлгаската археология, І. София: Арес, 1992, с. 199-203.

Кузев, 1983: КУЗЕВ Александър. - Две селски грънчарски пещи от XVII-XVIII в. Извистия на Народния музей - Варна, XIX, 1983, стр. 129-132.

Кузев, 1984: КУЗЕВ Александър. - Находки от грьнчарски пещи от XVII-XVIII в. във Варна. In: Сборник в памет на Станчо Ваклинов. София : 1984, стр. 208-210.

Цветков, 1989 : ЦВЕТКОВ Борис. - Керамика. In : ГЕОРГИЕВА Соня, НЕШЕВА Виолета (дир.). - Мелник. Том 1. Градът в подножието на Славова крепост. София: БАН, 1989, стр 120-159.

Генова, 1993а: ГЕНОВА Златка. — Късносредновековна битова керамика - XV-XVIII век /по археологически материали от В. Търново/. Дисертация за присъждане на степен «Кандидат на историческите науки». В. Търново: Археологически институт, БАН, 1993, 327 стр.+ LX табл.

Плетньов, 2000b: ПЛЕТНЬОВ Валентин. - Керамиката във Варна (XV - края на XVIII в.). Дисертация за получаване на научната и образователна степен «Доктор». В. Търново: Исторически факултет, 2000, 310 стр. + 887 фиг.

Генова, 1993b: ГЕНОВА Златка, За наименованията в българското грънчарство $X V$-XVIII в. Известия ня историческия музей В. Търново, 8, 1993, стр. 145-152.

Станчева, 1964: СТАНЧЕВА Магдалина. - Средновековна сграфито керамика от София. In: Сердика, т. I. София, 1964, стр. 169-187.

Овчаров, Овчаров, 1985 : ОВЧАРОВ Димитър, ОВЧАРОВ Николай. Уникални изображсения на ииркови игри във Велико Търново (XVIXVIII в.). Векове, 4, 1985, с. 49-53. 
Овчаров, 1992: ОВЧАРОВ Николай. - Корабоплаването по българското черноморско крайбрежсие (XIV-XIX в.). (По данни от рисунките-графити в иврквите в Несебър). София: Университетско изд. «Св. Климент Охридски », 1992, 120 с.

Станчева, 1976: СТАНЧЕВА Магдалина. - Художествени качества на българската керамика от епохата $X V$-XVII в. Традииии и нови черти в българското изкуство. София, 1976, с. 92.

Генова, 1993 : ГЕНОВА Златка. - За урасата на късносредновековната битова керамика от Велико Търново. ГХАМ, ІХ, 1993, стр. 197203.

Стайнова, 1995 : СТАЙНОВА Михаила - Османски изкуства на Балканите, XV - XVIII век. София: Унив. изд.«Св. Климент Охридски », 1995, 136 стр. + фиг. 


\section{Guergana GuiOnova, État de la recherche archéologique concernant la période} ottomane en Bulgarie

Les débuts et l'évolution de l'archéologie concernant la période ottomane en Bulgarie sont corrélatifs à l'accumulation de connaissances sur les sources écrites et l'ethnographie. En revanche, certaines données ont longtemps freiné son développement: la proximité chronologique, le vécu historique, le manque de parallèles bibliographiques et le contexte économique défavorable du passé proche. Toutefois, depuis les années trente, l'historiographie bulgare présente de façon systématique les résultats des recherches archéologiques. Au départ, l'accent est mis sur l'architecture, plus particulièrement les mosquées, puis sur les nécropoles, les lieux de culte et, par conséquent, sur la culture matérielle. La céramique est l'objet de nombreuses recherches et études de synthèse. De façon générale, les différentes structures, la numismatique et le mobilier tardifs sont davantage présents dans les rapports de fouilles, la réalité stratigraphique préoccupe de plus en plus de chercheurs. Par tradition, l'analyse stylistique prime lors de la considération de l'héritage matériel en raison de la quête de son caractère national. Des observations d'ordre technique seraient donc profitables pour l'avenir de la recherche archéologique sur l'époque ottomane en Bulgarie, ainsi que des études de synthèse basées sur l'accumulation des connaissances.

\section{Guergana Guionova, Present State of Bulgarian Archaeological Researches concerning the Ottoman Period}

The first Bulgarian archaeological researches concerning the Ottoman period and their development proceed along with the increasing knowledge of written sources and ethnology. This development however has been restrained for a long time by different factors : the chronological proximity of the said period, the mentality induced by the historical actual experience, the lack of bibliographical parallels, and the unfavourable economical context of the near past. However starting about 1930, Bulgarian historiography offers a systematic presentation of archaeological researches beginning with architecture, specially mosques, then necropolis, places of worship, and therefore material culture. Many researches and synthetic studies concern ceramics. As a rule, these past ten or twenty years, the different structures, numismatics, and late material are more and more often quoted in excavations reports, more and more research workers are concerned with stratigraphic reality. Traditionally, stylistic analysis takes the lead when a material discovery is concerned because of the quest for its national character. Technological observations would therefore be useful for the future of Ottoman archaeological researches in Bulgaria, as well as synthetic studies based on the actual accumulation of existent knowledge. 